\title{
Transplantation Related Toxicity and Mortality in Older Autologous Hematopoietic Cell Transplantation Recipients
}

\author{
Hewan Belete, MD¹, Linda J Burns, MD², Ryan Shanley, MS ${ }^{1}$, Manju Nayar, MBBS ${ }^{1}$, Brian \\ McClune, MD ${ }^{1}$, Aleksandr Lazaryan, MD, PhD ${ }^{1}$, Veronika Bachanova, MD ${ }^{1}$, Nelli Bejanyan, \\ MD ${ }^{1}$, Celalettin Ustun, $\mathbf{M D}^{1}$, Claudio Brunstein, MD, $\mathbf{P h D}^{1}$, Daniel J Weisdorf, $\mathbf{M D}^{1}$, and \\ Mukta Arora, MD, MS ${ }^{1}$ \\ ${ }^{1}$ University of Minnesota, Division of Hematology, Oncology and Transplantation, 420 Delaware \\ Street SE, Minneapolis, MN 55455 \\ ${ }^{2}$ National Marrow Donor Program, Minneapolis, MN
}

\begin{abstract}
With advances in supportive care, autologous hematopoietic cell transplant (AHCT) is increasingly being performed for patients older than 60 years. We analyzed patients receiving an AHCT for multiple myeloma or lymphoma in a contemporary cohort (2010-2012), with consistent treatment and supportive care and compared outcomes [CTCAE grade 3-5 toxicities, non-relapse mortality (NRM) and overall-survival (OS)] of younger ( $40-59$ years, $n=77$ ) versus older $(\succeq 60$ years, $n=67$ ) recipients. The proportion of patients with neutropenic infections was higher in the older group ( $64 \%$ vs. $44 \%$; $\mathrm{p}=0.02$ ). The proportion of patients with any grade $3-5$ toxicity was also higher in the older group ( $84 \%$ vs. $67 \%, \mathrm{p}=0.03$ ). In multivariate analysis, older age was significantly associated with higher odds (OR: $2.57,95 \%$ CI:1.09-6.05) of grade 3-5 toxicity. The NRM was 3\% (older) vs. $0 \%$ (younger) at one-year. The probability of OS at 2-years was lower in the older group ( $76 \%$ vs. $90 \%, \mathrm{p}=0.04$ ). Though AHCT can be performed safely in older recipients, the higher toxicity and slightly higher NRM in this population needs attention. Studies focusing on risk-stratification in older patients would further help predict toxicity. Further studies addressing enhanced supportive care needs for older patients who are most likely to benefit are indicated.
\end{abstract}

\section{Keywords}

Autologous hematopoietic cell transplant; transplant related mortality; older transplant recipients

\section{Introduction}

High dose chemotherapy and autologous hematopoietic stem cell transplant (AHCT) is an effective treatment strategy for many patients with lymphoma and multiple myeloma. ${ }^{1-4}$

Corresponding Author: Mukta Arora, Division of Hematology, Oncology and Transplant, University of Minnesota, 420 Delaware Street SE, Minneapolis, MN 55455. Phone 612626 4105. Fax: 612 625 6919. arora005@umn.edu.

Conflict-of-interest disclosure

The authors declare no competing financial interests. 
However, the procedure continues to be associated with complications, commonly including mucositis, infections, hematologic and other organ toxicities. ${ }^{5-8}$ The risk of morbidity and mortality is higher in older AHCT recipients as compared to younger AHCT recipients in some studies ${ }^{3,5,9}$, whereas other studies demonstrate similar outcomes in older versus younger patients. ${ }^{6-8}$ Recent advances in HCT strategies with improved supportive care have resulted in reduction in non-relapse mortality (NRM) and increased use of HCT in older recipients (> 60 years of age). ${ }^{10,11}$ Despite these advancements, the true burden of morbidity suffered by the elderly population after AHCT is still unknown. Therefore, we explored if age played a role in predicting transplantation related toxicity and mortality following AHCT. We analyzed patients receiving an AHCT for multiple myeloma or lymphoma in a contemporary cohort (2010-2012) receiving consistent treatment and supportive care and compared non-hematologic grade 3-5 toxicities [Common Toxicity Criteria for Adverse Events (CTCAE)] occurring within one year of AHCT, overall survival and NRM between the two groups. We hypothesized that with improved supportive care, there would be little or no difference in outcomes of younger (40-59 years) versus older ( 2 60 years) AHCT recipients.

\section{Patients and Methods}

Patients $\geq 40$ years of age who underwent an AHCT at the University of Minnesota between 2010 and 2012 for lymphoma (Hodgkin's or Non-Hodgkin's) or multiple myeloma were included in the study ( $\mathrm{n}=144)$. Approval for retrospective chart reviews was obtained from the Institutional Review Board (IRB) at University of Minnesota. Patients' demographic and HCT characteristics were retrieved from the University of Minnesota BMT database. Data regarding disease status at HCT, pre-HCT co-morbidity index (HCT-CI) ${ }^{12}$, survival status and underlying disease relapse or progression after HCT and non-hematologic grade 3-5 toxicities occurring within one year of HCT were abstracted through retrospective chart reviews. Toxicities were graded using the CTCAE version 4.0 of the National Cancer Institute. Adverse events were graded as 0 indicating none, $1=$ mild, $2=$ moderate, $3=$ severe, $4=$ life threatening or debilitating and $5=$ death.

\section{Statistical analysis}

The study is a retrospective cohort study. The primary endpoint was proportion of patients with grade 3-5 toxicities within one year of AHCT in younger (40-59 years old) versus older ( $\geq 60$ years old) groups. Secondary endpoints included time to neutrophil and platelet recovery, overall survival, and NRM. Neutrophil recovery was defined as the first day of an absolute neutrophil count $\geq 5 \times 10^{3} / \mu \mathrm{L}$ for 3 or more consecutive days; platelet recovery was defined as the first day of a platelet count $220 \times 10^{3} / \mu \mathrm{L}$ without transfusion support for 7 consecutive days. The patient, HCT and disease characteristics were described using descriptive characteristics and proportions between the two groups were compared using Fisher's exact test. The proportion of patients within each category of toxicity and those with any grade 3-5 toxicity were compared between groups using Fisher's exact test. OS was determined using the Kaplan-Meier estimation ${ }^{13}$ with $95 \%$ confidence intervals (CIs) derived from standard errors. Log rank testing was used to compare survival between the two groups. Cumulative incidence functions were used to estimate NRM. ${ }^{14}$ Multivariable 
logistic regression modeled the effect of age on the odds of having grade 3-5 toxicity, adjusting for other demographic, HCT related and disease related factors associated with toxicity incidence.

\section{Results}

The study included 144 patients $\geq 40$ years old. Demographics and HCT characteristics are described in table 1 . There were 77 patients in the young (40-59 years old) and 67 patients in the old ( 260 years old) group. The median age at transplant was 65 years (range 60-76 years) in the older group and 54 years (range 40-59 years) in the younger group. Median follow up time for both cohorts was 730 days. Multiple myeloma was the underlying diagnosis in $61 \%$ (old) vs $46 \%$ (young); non-Hodgkin's lymphoma in $37 \%$ (old) vs $40 \%$ (young) and Hodgkin's lymphoma in $2 \%$ vs $13 \%$ of the old group vs the young group, respectively. Patients with multiple myeloma (53\%) received high dose melphalan $\left(200 \mathrm{mg} / \mathrm{m}^{2}\right)$ as the pre-HCT conditioning regimen. $36 \%$ of both older and younger patients (all non-Hodgkin's lymphoma) received cyclophosphamide (Cy) with total body irradiation (TBI) (Cy $60 \mathrm{mg} / \mathrm{kg} \mathrm{IV} \mathrm{x} 2$ days plus TBI 165 cGy twice daily x 4 days) and $11 \%$ of the patients received cyclophosphamide, carmustine \& etoposide (CBV: Cy 1500mg/m2/day IV $\mathrm{x} 4$ days, Carmustine 300mg/m2 IV day 1 and etoposide $150 \mathrm{mg} / \mathrm{m} 2$ twice a day IV x 4 days) as conditioning regimen prior to HCT. $47 \%$ of younger patients compared to $27 \%$ of older patients were in complete remission at the time of transplant ( $\mathrm{p}=0.02)$. Over $95 \%$ of patients in both groups had a Karnofsky performance status (KPS) of $\geq 80 \%$ ( $\mathrm{p}=0.46$ ), while $27 \%$ in the older group versus $22 \%$ in the younger group had a HCT-CI comorbidity score of $\geq 3$ $(\mathrm{p}=0.72)$.

\section{Toxicities post HCT}

We examined 17 categories of non-hematologic grade 3-5 toxicities in both patient groups (Figure 1). The proportion of patients with any grade 3-5 toxicity was compared between the two groups. The frequency of each category (total no. (\%) of each category of toxicity) of toxicity was also compared between the older and younger groups. The proportion of patients with any grade $3-5$ toxicity was higher in the older group ( $84 \%$ vs. $67 \%, \mathrm{p}=0.03$ ). The frequency of neutropenic infections [infections with abnormal absolute neutrophil count $(\mathrm{ANC})<1000 / \mathrm{mm}^{3}$ ] was also higher in older HCT recipients $(64 \%$ versus $44 \%, \mathrm{p}=0.02)$. We did not identify any difference in the frequency of cardiovascular (7\% older versus $5 \%$ younger group, $\mathrm{p}=0.73$ ), respiratory toxicity ( $4 \%$ older versus $1 \%$ younger, $\mathrm{p}=0.34$ ), mucositis ( $19 \%$ older versus $10 \%$ younger, $\mathrm{p}=0.16$ ) or other toxicities between the older and younger age groups (Figure 1). We also compared the mean number of toxicities suffered by patients in older versus younger group. The mean number of grade 3-5 non-hematologic toxicities in the older age group [mean: 2.5 (range: 1-5)] was higher than that of the younger age group [mean 2 (range: $1-4)$ ], $\mathrm{p}=0.05$.

We evaluated the impact of conditioning regimen (TBI-based versus non-TBI based conditioning) on grade 3-5 toxicities. The proportion of patients receiving TBI-based conditioning was similar (36\% in both old and young) in both age groups. Use of TBI resulted in similar proportion of patients with grade 3-5 toxicities in the old and young 
groups ( $83 \%$ versus $82 \%$ in the old and young groups, respectively). In older patients, a high proportion of patients experienced grade $3-5$ toxicities regardless of the conditioning regimen ( $83 \%$ with TBI-based versus $84 \%$ with non-TBI-based conditioning). In younger patients, a slightly higher proportion (82\%) of patients experienced grade 3-5 toxicities amongst those who received TBI-based conditioning as compared to those without TBIbased conditioning (59\%).

\section{Risk factors for development of grade 3-5 toxicity}

A multivariable regression model was used to determine the odds of having at least one grade 3-5 toxicity (table 2). With adjustment for gender and disease, older age ( $\geq 60 \mathrm{y}$ ) was associated with significantly higher odds (OR: 2.57, 95\% CI: [1.09-6.05]) of developing grade 3-5 toxicity. We also calculated predicted probabilities of toxicity based on the odds for each variable. The predicted probability of grade 3-5 toxicities within one year (adjusted for age, gender and disease) was highest (94\%) in females $\geq 60$ years with Non-Hodgkin's lymphoma and lowest in males age 40-59 years with Hodgkin's lymphoma (47\%). (Table $3)$.

\section{Other outcomes}

We also compared time to neutrophil and platelet recovery, overall survival, and NRM within the first year post AHCT. There was no difference in time to neutrophil (median 11 days and 10 days in old and young groups, respectively) and platelet engraftment (median 18 days and 19 days in the old and young groups, respectively) between the two age groups. Two older recipients (cumulative incidence of NRM: 3\%, 95\% CI: 1-7\%) and no younger recipients had NRM within one year, $\mathrm{p}=0.05$. After a median follow-up of two years, the probability of overall survival at two years was lower in the older group (76\%, 95\% CI: $65-$ $87 \%$ ) vs. younger group (90\%, 95\%CI: 82-98\%), $\mathrm{P}=0.04$.

Overall twenty patients died within first two years of HCT, 14 in the older group and 6 in the younger group. All 6 patients in the younger group ( 5 with lymphoma, received Cy/TBI based conditioning; and one with multiple myeloma, received melphalan based conditioning) died of relapsed or progressive disease. Amongst the 14 patients in older group, 6 patients with multiple myeloma (all received melphalan based conditioning) died of relapsed or progressive disease (one also developed endometrial cancer), 5 patients with lymphoma (four received Cy/TBI based conditioning, one received CBV based conditioning) died of relapsed or progressive disease, two patients with lymphoma (both received Cy/TBI based conditioning) died of infections within one year of HCT, and one patient with lymphoma (received Cy/TBI based conditioning) died of metastatic urothelial cancer about two years after HCT.

\section{Discussion}

There is conflicting data regarding toxicity and mortality in older AHCT recipients versus younger AHCT recipients. ${ }^{3,5-7,9}$ The purpose of this study was to explore if age played a role in predicting transplantation related toxicity and mortality following AHCT for lymphoma and multiple myeloma. 
In our analysis, after adjustment for gender and disease, older age was significantly associated with higher odds of developing grade $3-5$ toxicities. These findings are consistent with other studies that reported increased frequency of specific toxicities such as cardiac toxicities, arrhythmias and oral or gastrointestinal toxicities among older patients with multiple myeloma undergoing hematopoietic cell transplant. ${ }^{5,15,16}$ More frequent mucositis, cardiovascular events and neurologic complications have also been reported in older patients with lymphoma undergoing AHCT. ${ }^{5,17-19}$ Higher toxicity in older patients might be explained by the fact that increased age is associated with increased co-morbid conditions and physiological changes resulting in diminished cardio-respiratory reserve. ${ }^{20,21}$ In our study, we did not find higher cardiac or oral or GI toxicities in the older versus younger groups. This difference may be because our selected older HCT cohort had similar comorbidities (as screened by HCT-CI) and KPS as our younger cohort. We found that the older group had a higher frequency of neutropenic infections as compared to the younger group, suggesting perhaps immunosenescence in the elderly HCT recipients. ${ }^{22}$

A multivariable regression model was used to estimate predicted probabilities of grade 3 to 5 toxicities within one year of HCT. The predicted probability of grade 3-5 toxicities within one year was highest in females older than 60 years with Non-Hodgkin's lymphoma and lowest in males 40-59 years with Hodgkin's lymphoma. Gender specific differences in toxicities have been previously reported, and have reported higher toxicities in women. ${ }^{23-25}$ The etiology behind these differences are unclear although differences in levels of metabolic enzymes and drug pharmacokinetics have been postulated. ${ }^{26}$ Patients with NHL at our institution were more likely to undergo chemotherapy using a TBI based regimen (cyclophosphamide and TBI) as compared to other diseases. (93\% of patients with NHL versus $0 \%$ in Hodgkin's lymphoma or $0 \%$ with multiple myeloma). Higher rates of death due to toxicity have been described in older patients with lymphoma undergoing a TBI based preparative regimen. ${ }^{27}$ Another report from Center for international Blood and Marrow Transplant Research (CIBMTR) compared different conditioning regimens in patients undergoing autologous HCT for lymphoma and reported higher risk of Idiopathic Pneumonia Syndrome (IPS) with TBI based regimens in patients with non Hodgkin's lymphoma, and higher mortality in patients with Hodgkin's lymphoma undergoing an AHCT with TBI based conditioning. ${ }^{3}$ We did not find a difference in toxicity by TBI-based versus non-TBI based conditioning in older recipients, however, in younger patients, a slightly higher proportion (82\%) of patients experienced grade 3-5 toxicities amongst those who received TBI-based conditioning as compared to those without TBI-based conditioning $(59 \%)$.

To conclude AHCT can be performed safely in older recipients. However, the higher toxicity and slightly higher NRM in this population needs attention. Studies focusing on riskstratification in older patients (including geriatric assessments) would further help predict toxicity. Further studies addressing enhanced supportive care needs for older patients who are most likely to benefit are indicated.

\section{Acknowledgments}

The work was supported in part by Leukemia and Lymphoma Society TRP: 6136-14 


\section{References}

1. Boyiadzis M, Pavletic S. Haematopoietic stem cell transplantation: indications, clinical developments and future directions. Expert Opin Pharmacother. 2004; 5(1):97-108. DOI: 10.1517/14656566.5.1.97 [PubMed: 14680439]

2. Hamadani M, Craig M, Awan FT, Devine SM. How we approach patient evaluation for hematopoietic stem cell transplantation. Bone Marrow Transplant. 2010; 45(8):1259-1268. DOI: 10.1038/bmt.2010.94 [PubMed: 20479713]

3. Chen YB, Lane AA, Logan BR, Zhu X, Akpek G, Aljurf MD, et al. Impact of conditioning regimen on outcomes for patients with lymphoma undergoing high-dose therapy with autologous hematopoietic cell transplantation. Biol Blood Marrow Transplant. 2015; 21(6):1046-1053. DOI: 10.1016/j.bbmt.2015.02.005 [PubMed: 25687795]

4. Palumbo A, Cavallo F, Gay F, Di Raimondo F, Ben Yehuda D, Petrucci MT, et al. Autologous transplantation and maintenance therapy in multiple myeloma. N Engl J Med. 2014; 371(10):895905. DOI: 10.1056/NEJMoa1402888 [PubMed: 25184862]

5. Mileshkin LR, Seymour JF, Wolf MM, Gates P, Januszewicz EH, Joyce P, et al. Cardiovascular toxicity is increased, but manageable, during high-dose chemotherapy and autologous peripheral blood stem cell transplantation for patients aged 60 years and older. Leuk Lymphoma. 2005; 46(11): 1575-1579. DOI: 10.1080/10428190500235884 [PubMed: 16236612]

6. Sirohi B, Powles R, Treleaven J, Mainwaring P, Kulkarni S, Pandha H, et al. The role of autologous transplantation in patients with multiple myeloma aged 65 years and over. Bone Marrow Transplant. 2000; 25(5):533-539. DOI: 10.1038/sj.bmt.1702188 [PubMed: 10713631]

7. Siegel DS, Desikan KR, Mehta J, Singhal S, Fassas A, Munshi N, et al. Age is not a prognostic variable with autotransplants for multiple myeloma. Blood. 1999; 93(1):51-54. [PubMed: 9864145]

8. Jantunen E, Mahlamaki E, Nousiainen T. Feasibility and toxicity of high-dose chemotherapy supported by peripheral blood stem cell transplantation in elderly patients ( $>/=60$ years) with nonHodgkin's lymphoma: comparison with patients $<60$ years treated within the same protocol. Bone Marrow Transplant. 2000; 26(7):737-741. DOI: 10.1038/sj.bmt.1702577 [PubMed: 11042654]

9. Sharma M, Zhang MJ, Zhong X, Abidi MH, Akpek G, Bacher U, et al. Older patients with myeloma derive similar benefit from autologous transplantation. Biol Blood Marrow Transplant. 2014; 20(11):1796-1803. DOI: 10.1016/j.bbmt.2014.07.013 [PubMed: 25046833]

10. Stamatoullas A, Brice P, Gueye MS, Mareschal S, Chevallier P, Bouabdallah R, et al. Autologous stem cell transplantation for patients aged 60 years or older with refractory or relapsed classical Hodgkin's lymphoma: a retrospective analysis from the French Society of Bone Marrow Transplantation and Cell Therapies (SFGM-TC). Bone Marrow Transplant. 2016; doi: 10.1038/ bmt.2016.76

11. Hermet E, Cabrespine A, Guieze R, Garnier A, Tempescul A, Lenain P, et al. Autologous hematopoietic stem cell transplantation in elderly patients ( $>$ /= 70 years) with non-Hodgkin's lymphoma: A French Society of Bone Marrow Transplantation and Cellular Therapy retrospective study. J Geriatr Oncol. 2015; 6(5):346-352. DOI: 10.1016/j.jgo.2015.04.005 [PubMed: 26116168]

12. Sorror ML, Maris MB, Storb R, Baron F, Sandmaier BM, Maloney DG, et al. Hematopoietic cell transplantation (HCT)-specific comorbidity index: a new tool for risk assessment before allogeneic HCT. Blood. 2005; 106(8):2912-2919. DOI: 10.1182/blood-2005-05-2004 [PubMed: 15994282]

13. Kaplan ELMP. Nonparametric estimation from incomplete observation. J Am Stat Assoc. 1958; 53(282):457-481.

14. Lin DY. Non-parametric inference for cumulative incidence functions in competing risks studies. Stat Med. 1997; 16(8):901-910. [PubMed: 9160487]

15. Muta T, Miyamoto T, Fujisaki T, Ohno Y, Kamimura T, Kato K, et al. Evaluation of the feasibility and efficacy of autologous stem cell transplantation in elderly patients with multiple myeloma. Intern Med. 2013; 52(1):63-70. [PubMed: 23291675]

16. Jantunen E, Kuittinen T, Penttila K, Lehtonen P, Mahlamaki E, Nousiainen T. High-dose melphalan $(200 \mathrm{mg} / \mathrm{m} 2)$ supported by autologous stem cell transplantation is safe and effective in elderly (>or=65 years) myeloma patients: comparison with younger patients treated on the same protocol. 
Bone Marrow Transplant. 2006; 37(10):917-922. DOI: 10.1038/sj.bmt.1705360 [PubMed: 16670701]

17. Jantunen E, Itala M, Juvonen E, Leppa S, Keskinen L, Vasala K, et al. Autologous stem cell transplantation in elderly (>60 years) patients with non-Hodgkin's lymphoma: a nation-wide analysis. Bone Marrow Transplant. 2006; 37(4):367-372. DOI: 10.1038/sj.bmt.1705266 [PubMed: 16415893]

18. Puig N, Pintilie M, Seshadri T, al-Farsi K, Franke N, Keating A, et al. High-dose chemotherapy and auto-SCT in elderly patients with Hodgkin's lymphoma. Bone Marrow Transplant. 2011; 46(10):1339-1344. DOI: 10.1038/bmt.2010.294 [PubMed: 21243027]

19. Wildes TM, Augustin KM, Sempek D, Zhang QJ, Vij R, Dipersio JF, et al. Comorbidities, not age, impact outcomes in autologous stem cell transplant for relapsed non-Hodgkin lymphoma. Biol Blood Marrow Transplant. 2008; 14(7):840-846. DOI: 10.1016/j.bbmt.2008.05.002 [PubMed: 18541205]

20. Strait JB, Lakatta EG. Aging-associated cardiovascular changes and their relationship to heart failure. Heart Fail Clin. 2012; 8(1):143-164. DOI: 10.1016/j.hfc.2011.08.011 [PubMed: 22108734]

21. Sharma G, Goodwin J. Effect of aging on respiratory system physiology and immunology. Clin Interv Aging. 2006; 1(3):253-260. [PubMed: 18046878]

22. Gavazzi G, Krause KH. Ageing and infection. Lancet Infect Dis. 2002; 2(11):659-666. [PubMed: 12409046]

23. van den Berg H, Paulussen M, Le Teuff G, Judson I, Gelderblom H, Dirksen U, et al. Impact of gender on efficacy and acute toxicity of alkylating agent -based chemotherapy in Ewing sarcoma: secondary analysis of the Euro-Ewing99-R1 trial. Eur J Cancer. 2015; 51(16):2453-2464. DOI: 10.1016/j.ejca.2015.06.123 [PubMed: 26271204]

24. Chansky K, Benedetti J, Macdonald JS. Differences in toxicity between men and women treated with 5-fluorouracil therapy for colorectal carcinoma. Cancer. 2005; 103(6):1165-1171. DOI: 10.1002/cncr.20878 [PubMed: 15693031]

25. Schmetzer O, Florcken A. Sex differences in the drug therapy for oncologic diseases. Handb Exp Pharmacol. 2012; (214):411-442. DOI: 10.1007/978-3-642-30726-3_19 [PubMed: 23027461]

26. Anderson GD. Gender differences in pharmacological response. Int Rev Neurobiol. 2008; 83:1-10. DOI: 10.1016/S0074-7742(08)00001-9 [PubMed: 18929073]

27. Sweetenham JW, Pearce R, Philip T, Proctor SJ, Mandelli F, Colombat P, et al. High-dose therapy and autologous bone marrow transplantation for intermediate and high grade non-Hodgkin's lymphoma in patients aged 55 years and over: results from the European Group for Bone Marrow Transplantation. The EBMT Lymphoma Working Party. Bone Marrow Transplant. 1994; 14(6): 981-987. [PubMed: 7711677] 


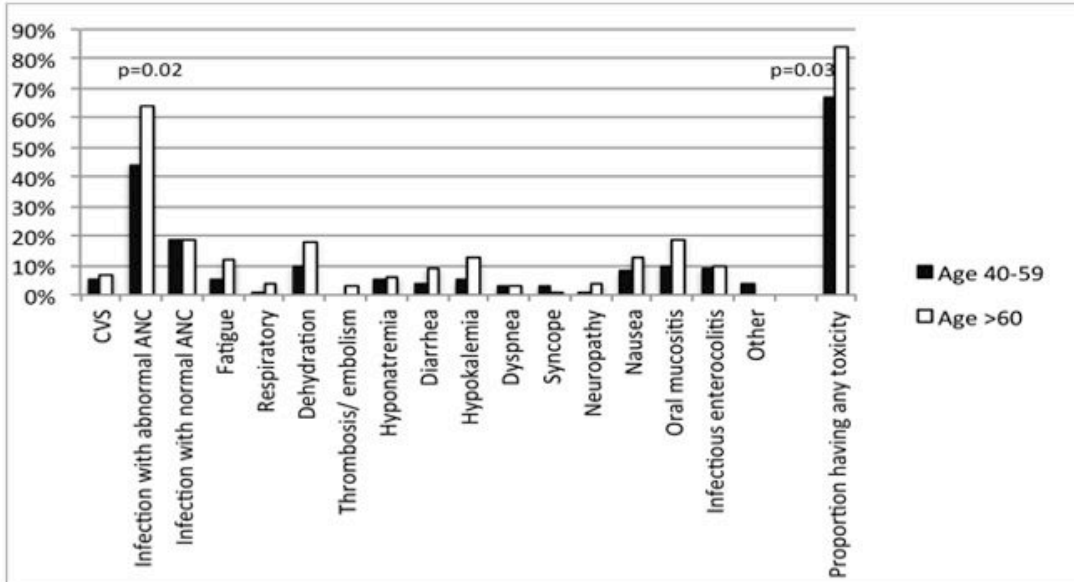

Figure 1.

Frequency of grade 3-5 toxicity in the first year post HCT.

Figure shows frequency of each category of toxicity within each age group

Abbreviation: CVS: cardiovascular system, ANC: absolute neutrophil count, HCT: hematopoietic cell transplant 


\section{Table 1}

Patient demographic and HCT characteristics

\begin{tabular}{|c|c|c|c|}
\hline & $\begin{array}{r}\text { Age 40-59 } \\
\text { n (\%) }\end{array}$ & $\begin{array}{r}\text { Age } \geq 60 \\
n(\%)\end{array}$ & $\mathbf{P}$ \\
\hline Number & $77(100 \%)$ & $67(100 \%)$ & \\
\hline \multicolumn{4}{|l|}{ Age } \\
\hline Median & 54 & 65 & \\
\hline Range & $40-59$ & $60-76$ & \\
\hline \multicolumn{4}{|l|}{ Gender } \\
\hline Male & $45(58)$ & $38(57)$ & .87 \\
\hline Female & $32(42)$ & $29(43)$ & \\
\hline \multicolumn{4}{|l|}{ Diagnosis } \\
\hline Hodgkin's lymphoma & $10(13)$ & $1(2)$ & .02 \\
\hline Non-Hodgkin's lymphoma & $31(40)$ & $25(37)$ & \\
\hline Multiple myeloma & $36(46)$ & $41(61)$ & \\
\hline \multicolumn{4}{|l|}{ Disease status at HCT } \\
\hline Complete Remission & $36(47)$ & $18(27)$ & .02 \\
\hline Partial Remission & $41(53)$ & $49(73)$ & \\
\hline \multicolumn{4}{|l|}{ Conditioning regimen } \\
\hline CY/BCNU/VP16 & $13(17)$ & $3(4)$ & .05 \\
\hline $\mathrm{CY} / \mathrm{TBI}$ & $28(36)$ & $24(36)$ & \\
\hline Melphalan & $36(47)$ & $40(60)$ & \\
\hline \multicolumn{4}{|l|}{ Karnofsky score } \\
\hline 100 & $31(40)$ & $20(30)$ & .46 \\
\hline 90 & $29(38)$ & $32(48)$ & \\
\hline 80 & $12(16)$ & $14(21)$ & \\
\hline 70 & $2(3)$ & $1(1)$ & \\
\hline Unknown & $3(4)$ & $0(0)$ & \\
\hline \multicolumn{4}{|l|}{ HCT comorbidity index } \\
\hline 0 & $32(42)$ & $31(46)$ & .72 \\
\hline $1-2$ & $23(30)$ & $17(25)$ & \\
\hline$\geq 3$ & $17(22)$ & $18(27)$ & \\
\hline Unknown & $5(6)$ & $1(1)$ & \\
\hline \multicolumn{4}{|l|}{ Recipient CMV status } \\
\hline Negative & $28(36)$ & $25(37)$ & .99 \\
\hline Positive & $49(64)$ & $42(63)$ & \\
\hline \multicolumn{4}{|l|}{ Stem cell source } \\
\hline PBSC & $75(97)$ & $67(100)$ & .50 \\
\hline Marrow+PBSC & $2(3)$ & $0(0)$ & \\
\hline HCT year & & & \\
\hline
\end{tabular}




\begin{tabular}{|l|r|r|r|}
\hline & $\begin{array}{r}\text { Age 40-59 } \\
\mathbf{n}(\mathbf{\%})\end{array}$ & $\begin{array}{r}\text { Age } \mathbf{2 6 0} \\
\mathbf{n}(\mathbf{\%})\end{array}$ & P \\
\hline 2010 & $15(19)$ & $14(21)$ & .47 \\
\hline 2011 & $35(45)$ & $36(54)$ & \\
\hline 2012 & $27(35)$ & $17(25)$ & \\
\hline Follow-up years & & & \\
\hline Median & 2.0 & 2.0 & .30 \\
\hline Range & $1.0-3.4$ & $1.0-3.4$ & \\
\hline
\end{tabular}

Abbreviations: $\mathrm{HCT}=$ hematopoietic cell transplantation; $\mathrm{CY}=$ cyclophosphamide; $\mathrm{TBI}=$ total body irradiation; $\mathrm{BCNU}=$ carmustine, $\mathrm{VP}-16=$ etoposide; $\mathrm{CMV}=$ cytomegalovirus; $\mathrm{PBSC}=$ peripheral blood stem cell 


\section{Table 2}

Multivariable regression modeling odds of having at least one grade 3-5 toxicity

\begin{tabular}{|c|c|c|c|c|}
\hline Factor & N & Odds Ratio & 95\% CI & P \\
\hline Age 40-59 & 77 & 1.00 & & \\
\hline Age 60-76 & 67 & 2.57 & $1.09-6.05$ & .03 \\
\hline Male & 83 & 1.00 & & \\
\hline Female & 61 & 2.24 & $0.96-5.24$ & .06 \\
\hline Multiple myeloma & 77 & 1.00 & & \\
\hline Hodgkin's lymphoma & 11 & 0.82 & $0.21-3.18$ & .77 \\
\hline Non-Hodgkin's lymphoma & 56 & 2.67 & $1.07-6.68$ & .04 \\
\hline
\end{tabular}

An odds ratio $>1$ represents a greater risk of toxicity. 


\section{Table 3}

Predicted probabilities of developing grade 3-5 toxicity from logistic regression model. Actual results from of our patient population are displayed for reference.

\begin{tabular}{|l|l|l|l|l|}
\hline & $\begin{array}{l}\text { Age 40-59 } \\
\text { male }\end{array}$ & $\begin{array}{l}\text { Age 40-59 } \\
\text { female }\end{array}$ & $\begin{array}{l}\text { Age } \mathbf{2 6 0} \\
\text { male }\end{array}$ & $\begin{array}{l}\text { Age } \geq 60 \\
\text { female }\end{array}$ \\
\hline Multiple Myeloma & $\begin{array}{l}\text { Predicted: } 52 \% \\
\text { Actual: } 7 / 16\end{array}$ & $\begin{array}{l}\text { Predicted: } 71 \% \\
\text { Actual: } 13 / 19\end{array}$ & $\begin{array}{l}\text { Predicted: 73\% } \\
\text { Actual: } 17 / 22\end{array}$ & $\begin{array}{l}\text { Predicted: } 86 \% \\
\text { Actual: } 17 / 19\end{array}$ \\
\hline Hodgkin's lymphoma & $\begin{array}{l}\text { Predicted: } 47 \% \\
\text { Actual: } 3 / 7\end{array}$ & $\begin{array}{l}\text { Predicted: } 67 \% \\
\text { Actual: } 2 / 3\end{array}$ & $\begin{array}{l}\text { Predicted: } 70 \% \\
\text { Actual: } 1 / 1\end{array}$ & $\begin{array}{l}\text { Predicted: } 82 \% \\
\text { Actual: } 0 / 0\end{array}$ \\
\hline Non Hodgkin's lymphoma & $\begin{array}{l}\text { Predicted: 75\% } \\
\text { Actual: } 16 / 20\end{array}$ & $\begin{array}{l}\text { Predicted: } 87 \% \\
\text { Actual: } 9 / 10\end{array}$ & $\begin{array}{l}\text { Predicted: } 88 \% \\
\text { Actual: } 12 / 15\end{array}$ & $\begin{array}{l}\text { Predicted: } 94 \% \\
\text { Actual: } 9 / 10\end{array}$ \\
\hline
\end{tabular}

